\title{
ESTOQUE INDIVIDUAL DE BIOMASSA E CARBONO EM Nectandra grandiflora Nees (CANELA-AMARELA)
}

\author{
Gislaine Vieira ${ }^{1}$, Carlos Roberto Sanquetta ${ }^{2}$, Laércio da Silveira Soares Barbeiro ${ }^{3}$ \\ ${ }^{1}$ Acadêmica de Farmácia e Bioquímica, PUCPR, Curitiba, PR, Brasil - gigi_farma@hotmail.com \\ ${ }^{2}$ Eng. Florestal, Ph.D., Depto. de Ciências Florestais, UFPR, Curitiba, PR, Brasil - sanquetta@ufpr.br \\ ${ }^{3}$ Acadêmico de Engenharia Florestal, UFPR, Curitiba, PR, Brasil - laeguitar@ hotmail.com \\ Recebido para publicação: 12/06/2008 - Aceito para publicação: 28/10/2008
}

\begin{abstract}
Resumo
Reflorestamento foi previsto no Protocolo de Quioto como projeto de créditos de carbono, porém são escassos os estudos com espécies nativas brasileiras. Este trabalho teve como objetivo quantificar o estoque de carbono fixado em Nectandra grandiflora Nees, através da análise de seus teores de carbono e estoque de biomassa seca. Os dados compõem-se de 30 árvores coletadas em São João do Triunfo (PR). Cada árvore foi dividida nos componentes folhagem, galhos, fustes e raízes. O material passou por secagem, pesagem, trituração, moagem e determinação dos teores de carbono. Análises estatísticas foram feitas e um modelo individual de carbono em função do diâmetro foi desenvolvido. A média dos teores de carbono para folhagem foi de $44,1 \%$, para galhos vivos $42,7 \%$, raiz $42,4 \%$ e fuste $42,1 \%$, com uma média ponderada de $42,3 \%$, valor inferior ao default do IPCC. A folhagem apresentou teores de carbono significativamente maiores em todos os compartimentos analisados. A maior fração de biomassa seca na espécie está no fuste, seguido de galhos, raízes e folhagem. Concluiu-se que a equação PCTotal $=\exp [-2,26388+2,38201 \times \operatorname{Ln}($ dap $)] \times 0,42334$ representa satisfatoriamente o comportamento do estoque de carbono em função do dap na espécie.

Palavras-chave: Canela-amarela; fixação de carbono; $\mathrm{MDL}$; remoção de $\mathrm{CO}_{2}$.
\end{abstract}

\begin{abstract}
Individual biomass and carbon stock for Nectandra grandiflora Nees (canela-amarela). Reforestation was taken into consideration in the Kyoto Protocol, but there are few studies on Brazilian native species. This paper aimed at quantifying the carbon stocked by Nectandra grandiflora Nees, through the analysis of its carbon fraction and dry biomass weight. The data came from 30 trees harvested in São João do Triunfo municipality (PR). Each tree separated into four components: foliage, branches, trunk and roots. The material was submitted to lab procedures, i.e., drying, weighting, triturating, grinding and carbon determination. Analyses were carried out and an individual tree carbon stock model as a function of dbh was developed. The mean carbon fraction was: $44.1 \%$ for foliage, $42.7 \%$ for branches, $42.4 \%$ for roots and $42.1 \%$ for the trunk, and the weighted average was $42.3 \%$, lesser than the IPCC default. Foliage showed carbon fractions significantly greater than the other biomass components analyzed. The distribution of dry biomass in the studied species was mostly in the trunk, and afterwards in the branches, roots and, finally, foliage. It was concluded that the equation PCTotal $=\exp [-2.26388+2.38201 \times \operatorname{Ln}(\mathrm{dap})] \times 0.42334$ represents adequately the behavior of the carbon stock in the species studied.
\end{abstract}

Keywords: Canela-amarela; carbon sink; $\mathrm{CDM} ; \mathrm{CO}_{2}$ removal.

\section{INTRODUÇÃO}

$\mathrm{O}$ aumento das emissões de gases de efeito estufa interfere no balanço radiativo da atmosfera, o que, a longo prazo, tem levado a um aumento da temperatura média da Terra. As maiores fontes de emissão desses gases incluem a queima de combustíveis fósseis, as mudanças no uso da terra e a agricultura, que liberam $\mathrm{CO}_{2}$ e outros gases poluentes para a atmosfera. A redução dos níveis de $\mathrm{CO}_{2}$ na atmosfera tornou-se um dos maiores desafios do homem na virada do milênio (KOEHLER et al., 2002).

Plantações florestais realizam o processo inverso dessa queima, através da fotossíntese, que captura o carbono da atmosfera, estocando-o em forma de biomassa. O conceito de sequestro de carbono 
foi consagrado na Conferência de Quioto, em 1997, com o objetivo de conter e reverter o acúmulo de $\mathrm{CO}_{2}$ na atmosfera para reduzir o efeito estufa (CHANG, 2004).

O conhecimento dos teores de carbono e suas quantidades estocadas na biomassa é de fundamental importância para se poder desenvolver projetos de sequestro biológico ou biofixação em um determinado ecossistema, bem como para se poder realizar uma avaliação adequada dos impactos que supostamente a retirada do material (biomassa) possa vir a provocar no ambiente. Portanto, a avaliação concisa e fidedigna da biomassa é parte imprescindível e fundamental dos estudos que visam à quantificação da captura de carbono pelas florestas (SANQUETTA et al., 2004).

Os estudos científicos sobre a espécie Nectandra grandiflora são escassos, muito embora esta e outras espécies da família Lauraceae estejam entre as mais comuns na estrutura da Floresta de Araucária. Segundo Pizatto (1999), ela é uma das espécies de melhor regeneração na floresta, mas seu porte é pequeno, não sendo considerada como de grande expressão madeireira. Por outro lado, várias substâncias contidas na biomassa dessa espécie estão sendo prospectadas, pois há indícios do seu potencial fitofármaco. Segundo Ribeiro (2002), o fracionamento cromatográfico do extrato etanólico das suas folhas resultou no isolamento de dois flavonoides glicosilados que apresentaram atividade antioxidante, inibindo a oxidação do b-caroteno.

Estudos estão sendo desenvolvidos com o objetivo de se quantificar o carbono estocado na biomassa dessa espécie, com dois enfoques: caracterizar seus compostos orgânicos e avaliar a possibilidade de utilização dessa espécie em projetos de sequestro de carbono, seja com fins comerciais, seja de restauração ambiental. O presente trabalho tem como objetivo quantificar os teores e os estoques de carbono presentes na biomassa individual de espécimes de Nectandra grandiflora Nees, com ênfase na análise estatística desses teores dentro de cada compartimento analisado (folhagem, fuste, galhos e raízes) e no ajuste de um modelo matemático para estimar o peso em carbono a partir de uma variável de fácil obtenção, no caso o DAP (diâmetro à altura do peito).

\section{MATERIAIS E MÉTODOS}

\section{Descrição da área de estudo}

Este estudo foi realizado no município de São João do Triunfo, que se localiza na região centrosul do Paraná. A altitude do local é de $780 \mathrm{~m}$, a latitude Sul de $25^{\circ} 34^{\prime} 18^{\prime \prime}$ e a longitude Oeste de 5005'56" de Greenwich (PIZATTO, 1999).

Segundo a classificação de Koeppen, o clima da região é tipo Cfb (LONGHI, 1980; RODRÍGUEZ TELLO, 1980; PIZATTO, 1999; DURIGAN, 1999), caracterizado por ser mesotérmico, sempre úmido e com verões brandos. O clima é típico do planalto meridional brasileiro, com temperaturas médias anuais entre 14 e $19{ }^{\circ} \mathrm{C}$ e precipitação anual entre 1.250 e $2.000 \mathrm{~mm}$. Dados climáticos médios obtidos das estações meteorológicas do IAPAR nos municípios da Lapa, Fernandes Pinheiro e Ponta Grossa, próximos à área de estudo (adaptado de DURIGAN, 1999), indicam temperatura média anual de $17,4^{\circ} \mathrm{C}$, umidade relativa média anual de $80,1 \%$, precipitação média anual de $1.615 \mathrm{~mm}$, sendo janeiro o mês mais chuvoso e agosto, o mais seco.

Durigan (1999), por meio de prospecções realizadas também nessa Estação Experimental, identificou a ocorrência de Latossolo Vermelho-Escuro e Latossolo Vermelho-Amarelo, além de Cambissolos (Cambissolo gleico, nas cotas mais baixas) e Neossolos Litólicos.

Baseando-se na classificação proposta pelo IBGE (1992), a tipologia vegetal dominante na área é a Floresta Ombrófila Mista ou Floresta com Araucária, onde predominam como espécies arbóreas o pinheiro-do-paraná (Araucaria angustifolia), a erva-mate (Ilex paraguariensis), a imbuia (Ocotea porosa), a bracatinga (Mimosa scabrella), as canelas (Ocotea e Nectandra, principalmente) e várias espécies da família Myrtaceae.

Apesar de não ter sofrido corte raso, a floresta em questão já foi alterada por extração de madeira. Isso permite enquadrá-la como uma vegetação primária alterada ou formação secundária avançada, visto que possui algumas características estruturais de formações primárias associadas a intervenções antrópicas que caracterizam formações secundárias (SCHAAF, 2001).

\section{Descrição da espécie}

Nectandra grandiflora Nees ocorre do estado de Minas Gerais ao Rio Grande do Sul, em matas ciliares, capoeiras e na mata de pinhais, em altitudes compreendidas entre 600 e $1300 \mathrm{~m}$. É particularmente frequente no Segundo Planalto Paranaense (LORENZI, 1998). Participa da composição 
florística da Floresta Ombrófila Densa, da Floresta Ombrófila Mista e da Floresta Estacional Decidual (MARCHIORI, 1997). Segundo Pizatto (1999), essa espécie apresenta elevados valores de importância na estrutura fitossociológica na floresta de São João do Triunfo, sendo a segunda mais abundante (61 ind./ha) e mais frequente $(37,14 \%)$.

\section{Preparação das amostras para as análises}

As amostras deste estudo foram coletadas no primeiro trimestre do ano de 2007 e fazem parte do Programa de Pesquisas Ecológicas de Longa Duração, Site 9 (PELD), financiado pelo Conselho Nacional de Desenvolvimento Científico e Tecnológico (CNPq).

Foram abatidas 30 árvores da espécie, as quais foram derrubadas, separadas e identificadas em todos os seus compartimentos, ou seja, folhagem, fustes, galhos e raízes, resultando num total de 120 unidades de trabalho (4 compartimentos x 30 árvores). Antes da derrubada, essas árvores foram medidas em CAP, empregando-se fita métrica de fibra e transformando essa medida em DAP. Esse material foi pesado na sua forma verde no campo, utilizando balanças de vara (pêndulo), obtendo-se assim o peso fresco de cada componente. As amostras foram acondicionadas em sacos de ráfia e enviadas ao laboratório, onde foram submetidas à secagem em estufa a uma temperatura de $40^{\circ} \mathrm{C}$, até peso constante. Após a secagem realizou-se a determinação do peso seco de cada amostra. Cada componente passou pelo processo de fracionamento em partes pequenas utilizando machado, sendo posteriormente triturado em moinho de seis facas com peneiras metálicas até adquirir a consistência de pó. Cuidado foi tomado para não haver contaminação das amostras, mediante a limpeza do moinho com jato de ar comprimido a cada amostra moída. Elas foram acondicionadas e identificadas em potes de plástico. As amostras já preparadas foram analisadas no Laboratório de Inventário Florestal da Universidade Federal do Paraná, conforme descrito a seguir.

\section{Determinação dos teores de carbono}

Após a preparação das amostras, foram realizadas as determinações de carbono em analisador modelo Leco C-144. Nesse método, a amostra de material sólido é levada à combustão total em câmara de cerâmica infravermelho. O procedimento laboratorial consiste em pesar uma porção de $100 \mathrm{mg}$ de cada amostra em balança analítica e submetê-la à temperatura de $1.000^{\circ} \mathrm{C}$ por cerca de 60 segundos. $\mathrm{O}$ software instalado em um computador conectado ao aparelho permite verificar se houve queima completa da amostra e informa o respectivo teor de carbono da amostra diretamente em tela, gravando também um arquivo para uso posterior.

\section{Análises estatísticas}

As análises estatísticas descritivas e experimentais foram processadas por meio do programa Statistica, a fim de analisar suas medidas de tendência central e dispersão e verificar se, estatisticamente, existem diferenças de teores de carbono entre os compartimentos da espécie Nectandra grandiflora. Utilizou-se o teste de ANOVA (Análise de Variância), para averiguar se houve diferenças significativas nas análises. Logo após esse procedimento, o teste de Tukey foi aplicado para se realizar a comparação das médias entre as distintas partes das árvores e compartimentos. Procedimentos de modelagem foram então implementados se para construir a equação final de estimativa de estoque individual de carbono a partir dos trabalhos desenvolvidos por Barbeiro et al. (2008).

\section{RESULTADOS}

\section{Teores de carbono}

Os resultados dos teores de carbono das 30 árvores abatidas separadas em quatro compartimentos são apresentados na Tabela 1. Observa-se que as variações foram de cerca de 42 a $44 \%$. Considerando todos os compartimentos, o valor médio ponderado dos teores foi de 42,33\%, valores bem inferiores aos tomados como default pelo Intergovernmental Panel on Climate Change (IPCC, 2003), ou seja, em geral, nos projetos de créditos de carbono ocorrem superestimativas dos estoques em função de se usar o valor 50\% como referência. As variações também podem ser expressas pelos desvios padrões e pelos coeficientes de variação, os quais são bastante baixos comparativamente a outras variáveis geralmente tomadas em estudos de biomassa, oscilando entre 1,6 a 3,6\%. Os valores máximos e mínimos apresentados na tabela 1 também dão ideia da amplitude dos valores dos teores de carbono na espécie, o que é consistente com outras pesquisas semelhantes. 
Tabela 1. Estatísticas descritivas dos teores de carbono por compartimento da biomassa em Nectandra grandiflora Nees.

Table 1. Descriptive statistics of carbon content per biomass components of Nectandra grandiflora Nees.

\begin{tabular}{lccccc}
\hline Compartimento & Média & Desvio padrão & CV\% & Máximo & Mínimo \\
\hline Folhagem & 44,114 & 0,7685 & 1,7421 & 46,432 & 42,875 \\
Galhos & 42,428 & 1,5283 & 3,6021 & 45,050 & 37,935 \\
Raízes & 42,765 & 0,6997 & 1,6362 & 44,481 & 41,786 \\
Fuste & 42,106 & 1,2054 & 2,8628 & 44,057 & 38,370 \\
\hline Média ponderada & 42,334 & & & &
\end{tabular}

Na tabela 2 verifica-se que houve diferença significativa entre as médias dos teores de carbono dos compartimentos. Conforme se pode visualizar na figura 1, a folhagem possui a maior média, a qual difere estatisticamente da média dos demais compartimentos pelo teste de Tukey a $1 \%$ de probabilidade de confiança. Os demais compartimentos não diferem entre si estatisticamente pelo teste.

Tabela 2. ANOVA para teores de carbono em cada compartimento em Nectandra grandiflora Nees.

Table 2. ANOVA for carbon content in each biomass components for Nectandra grandiflora Nees.

\begin{tabular}{lccccc}
\hline $\begin{array}{l}\text { Fonte de } \\
\text { variação }\end{array}$ & $\begin{array}{c}\text { Soma de } \\
\text { quadrados }\end{array}$ & $\begin{array}{c}\text { Graus de } \\
\text { liberdade }\end{array}$ & $\begin{array}{c}\text { Quadrado } \\
\text { médio }\end{array}$ & F calculado & F tabelado \\
\hline Compartimento & 70,12845 & 3 & 23,37615 & $19,20384^{* * *}$ & 2,682809 \\
Resíduo & 141,2026 & 116 & 1,217264 & & \\
\hline Total & 211,3311 & 119 & & & \\
\hline ** Diferenças ao nível de $1 \%$ de prabidade & & & &
\end{tabular}

** Diferenças ao nível de 1\% de probabilidade de confiança.

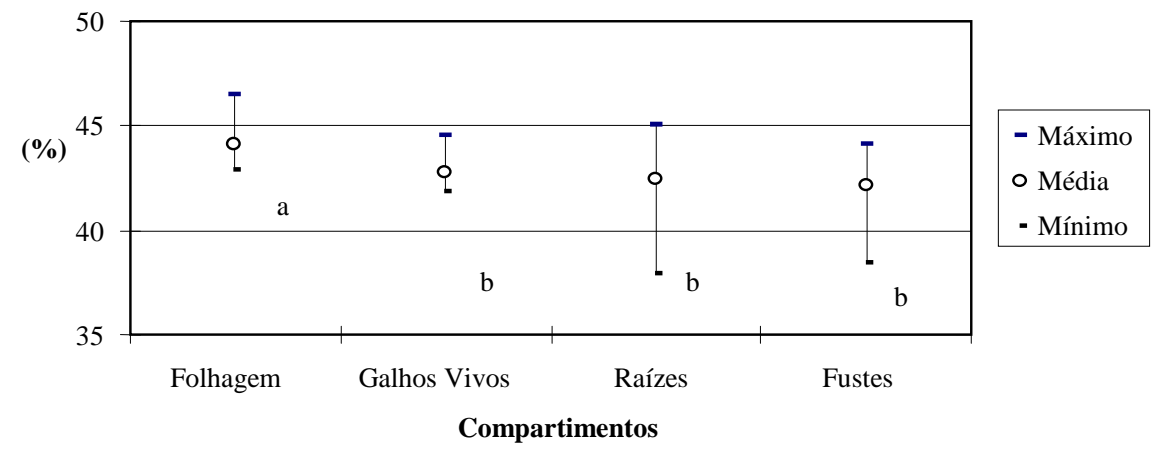

Figura 1. Teor médio de carbono e amplitude para cada compartimento em Nectandra grandiflora Nees. Figure 1. Mean carbon content and width for Nectandra grandiflora Nees.

Em Araucaria angustifolia, Weber et al. (2003) encontraram teores médios de carbono para o fuste de $44,1 \%$, para a folhagem de $44,0 \%$, para galhos mortos de $42,9 \%$, para galhos vivos de $41,7 \%$, para raízes de $40,5 \%$ e para casca de $40,1 \%$. Weber et al. (2006), trabalhando com outras seis espécies da Floresta Ombrófila Mista, encontraram os seguintes teores médios de carbono: 42,2\% em Myrsine ferruginea, 41,8\% em Ocotea porosa, 41,3\% em Ilex paraguariensis, 41,0\% em Mimosa scabrella, $40,7 \%$ em Symplocos uniflora e 39,9\% em Styrax leprosus. Em Mimosa scabrella, Urbano (2007) encontrou valores para os teores de carbono de $45,46 \%$ para as folhas, $44,69 \%$ para a casca, $44,13 \%$ para galhos inferiores a $4 \mathrm{~cm}$ de diâmetro, $43,94 \%$ para galhos superiores a $4 \mathrm{~cm}$ de diâmetro e $43,68 \%$ para o fuste. Portanto, os valores encontrados neste estudo estão condizentes com os de outros pesquisadores trabalhando na mesma ecorregião, ou seja, os valores gravitam entre 40 e $45 \%$, aproximadamente, para 
todos os compartimentos. Dependendo da espécie e das condições ambientais, os teores de carbono variam, mas sempre destro de um mesmo espectro. É importante salientar que os valores encontrados (neste estudo e por outros pesquisadores) são sempre inferiores ao referencial de $50 \%$ amplamente utilizado em metodologias de quantificação de carbono em plantas.

\section{Biomassa seca}

A biomassa seca das 30 árvores amostradas (Tabela 3) foi obtida após sua pesagem em campo e retirada de amostras para determinação do peso seco em laboratório, conforme explicado previamente. Os DAPs das árvores variaram de 9,23 a 32,47 cm, com média aritmética de 15,47 cm, valores correspondentes à amplitude encontrada na floresta (PIZATTO, 1999).

Tabela 3. Estatísticas descritivas dos valores de biomassa seca em cada compartimento em Nectandra grandiflora Nees.

Table 3. Descriptive statistics of dry biomass values per biomass components for Nectandra grandiflora Nees.

\begin{tabular}{lccccc}
\hline Compartimento & Média & Desvio padrão & CV\% & Máximo & Mínimo \\
\hline Folhagem & 2,58 & 2,5742 & 99,77 & 11,98 & 0,39 \\
Galhos & 21,72 & 32,0830 & 147,71 & 164,70 & 1,85 \\
Raízes & 12,22 & 17,5088 & 143,28 & 94,25 & 2,29 \\
Fuste & 52,11 & 48,1601 & 92,42 & 212,26 & 8,97 \\
\hline Total & 88,62 & 97,4519 & 109,97 & 483,19 & 17,82 \\
\hline
\end{tabular}

Em termos percentuais, a biomassa seca se distribuiu nas plantas da seguinte forma: cerca de $59 \%$ no fuste, $24 \%$ nos galhos, $14 \%$ nas raízes e $3 \%$ na folhagem, conforme pode ser visto na figura 2 a.
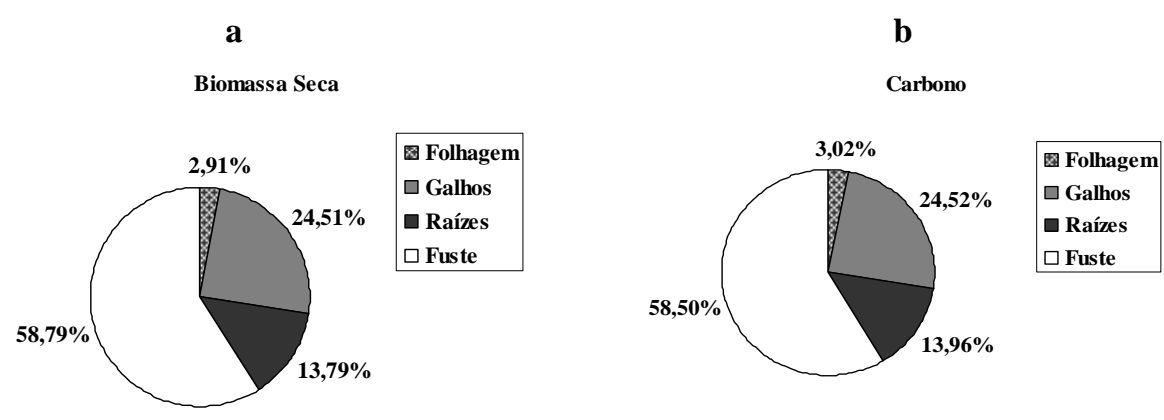

Figura 2. Proporção de biomassa seca e carbono em 30 árvores de Nectandra grandiflora Nees.

Figure 2. Proportion of dry weight of biomass components in 30 sample trees of Nectandra grandiflora Nees.

Alves (2007), ao quantificar a biomassa em clones de eucaliptos com aproximadamente 4 anos, encontrou para os compartimentos os seguintes percentuais: galhos $(11,05 \%)$, folhagem $(7,44 \%)$, casca $(7,90 \%)$ e fuste $(61,61 \%)$. Watzlawick (2003), em uma Floresta Ombrófila Mista Montana, em General Carneiro, estado do Paraná, encontrou na biomassa seca os seguintes percentuais: fuste $(50,52 \%)$, galhos vivos $(45,01 \%)$, galhos mortos $(1,16 \%)$, folhagem $(2,40 \%)$ e miscelânea $(0,97 \%)$. Já Urbano (2007), estudando bracatingais nativos da Região Metropolitana de Curitiba, encontrou valores para biomassa seca de $69,82 \%$ para fuste, $11,51 \%$ para galhos inferiores a $4 \mathrm{~cm}$ de diâmetro, $9,28 \%$ para galhos superiores a $4 \mathrm{~cm}, 5,57 \%$ para as folhas e $3,83 \%$ para os galhos mortos. Para Nectandra grandiflora não existem referências a respeito da distribuição da biomassa seca, porém a maior parte dela concentrou-se no fuste, com $52,11 \%$, coincidindo, de forma geral, com a literatura que indica que nas espécies florestais a maior fração da biomassa encontra-se no caule. Folhagem, galhos e raízes vêm em seguida, dependendo da espécie e de sua arquitetura. No caso de Nectandra grandiflora, a segunda maior fração de biomassa seca foi nos galhos, pois trata-se de uma espécie com ramificação simpodial e presença de densa galhada. 
Percebeu-se um valor baixo para biomassa seca da folhagem na espécie estudada, como nos trabalhos de Watzlawick (2003) e Urbano (2007).

\section{Estoque individual de carbono}

As estatísticas descritivas dos valores de estoque individual de carbono são apresentadas na tabela 4. Nota-se que o estoque médio individual por árvore, somando-se todos os compartimentos, foi de $37,80 \mathrm{~kg}$, com valores mínimos e máximos de 7,62 e $209,18 \mathrm{~kg}$, respectivamente. A distribuição do estoque de carbono nos compartimentos seguiu padrão semelhante ao da biomassa seca, devido ao fato de os teores de carbono serem estáveis, na faixa de 40 a $45 \%$. Em termos percentuais, o estoque individual de carbono se distribui na planta da seguinte forma: cerca de $60 \%$ no fuste, $22 \%$ nos galhos, $14 \%$ nas raízes e $3 \%$ na folhagem, seguindo a tendência da biomassa seca, conforme pode ser visto na Figura $2 \mathrm{~b}$.

Tabela 4. Estoque individual de carbono em árvores da espécie Nectandra grandiflora Nees.

Table 4. Individual carbon stock in trees of Nectandra grandiflora Nees.

\begin{tabular}{lccccc}
\hline Compartimento & Média & Desvio padrão & CV \% & Máximo & Mínimo \\
\hline Folhagem & 1,14 & 1,14 & 100,28 & 5,32 & 0,17 \\
Galhos & 9,27 & 13,76 & 148,51 & 70,48 & 0,79 \\
Raízes & 5,28 & 7,74 & 146,63 & 41,92 & 0,97 \\
Fuste & 22,12 & 20,79 & 93,98 & 91,45 & 3,79 \\
Total & 37,80 & 42,14 & 111,48 & 209,17 & 5,72 \\
\hline
\end{tabular}

\section{Modelo individual de carbono}

Com base nos valores de peso de carbono individual e os respectivos valores de DAP das 30 árvores-amostras foram testados vários modelos matemáticos (BARBEIRO et al., 2008), entre os quais foi eleito o melhor para aplicação neste trabalho. A equação resultante foi a seguinte:

$$
\text { PCTotal }=\exp [-2,26388+2,38201 \times \operatorname{Ln}(\text { dap })] \times 0,42334
$$

Aplicando-se a equação acima, foi obtido o modelo individual de estoque de carbono para biomassa acima do solo e abaixo do solo expresso na figura 3.

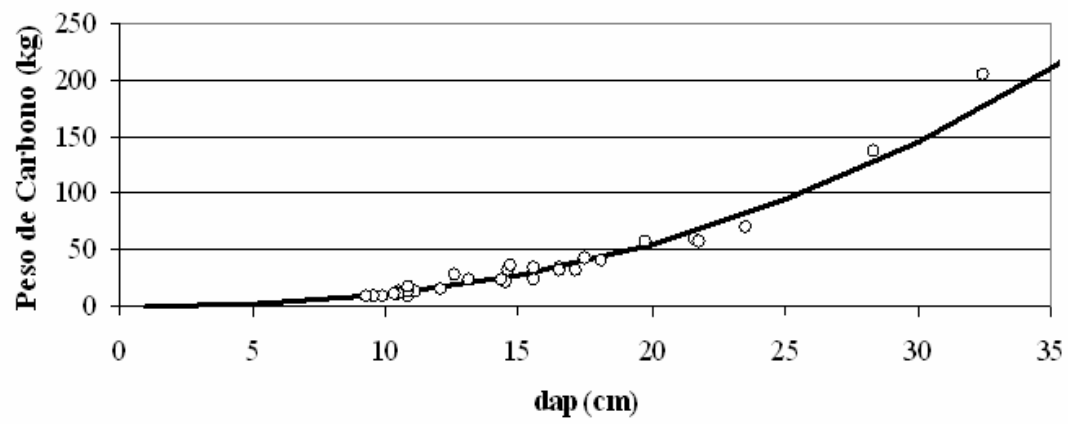

Figura 3. Modelo de estoque individual de carbono em Nectandra grandiflora Nees em função do DAP. Figure 3. Individual model of carbon stock for Nectandra grandiflora Nees as a function of DBH.

\section{CONCLUSÕES}

- O compartimento que apresentou maior concentração de carbono foi a folhagem.

- A média ponderada dos teores de carbono encontrados nesta pesquisa foi bem inferior ao sugerido como default pelo IPCC (50\%). 
- A maior fração de biomassa seca na espécie estudada está no seu fuste, seguido de galhos, raízes e folhagem.

- O peso da árvore média dessa espécie, com DAP médio de $15,47 \mathrm{~cm}$, é de $88,62 \mathrm{~kg}$, equivalente a $37,80 \mathrm{~kg}$ de carbono, ou seja, $138,60 \mathrm{~kg}$ de $\mathrm{CO}_{2}$ equivalente.

- $\quad$ O modelo PCTotal $=\exp [-2,26388+2,38201 \times \operatorname{Ln}($ dap) $] \times 0,42334$ representa satisfatoriamente $\mathrm{o}$ comportamento do estoque individual de carbono em função do DAP da árvore da espécie em apreço. Esse modelo pode ser aplicado em projetos de reflorestamento voltados ao mercado de créditos de carbono, pois se pode, a partir dele, fazer a estimativa das remoções de $\mathrm{CO}_{2}$ para o período de creditação sem precisar derrubar árvores para esse fim, apenas com medições através de inventário florestal convencional.

\section{REFERÊNCIAS}

ALVES, A. M. C. Estimativa da produção de biomassa e do teor de carbono seqüestrado por clones de eucaliptos, no pólo gessseiro do Araripe-PE. 61 p. Dissertação (Mestrado em Engenharia Florestal) - Universidade Federal Rural de Pernanbuco, Recife, 2007.

BARBEIRO L. S. S.; VIEIRA, G.; SANQUETTA, C. R. Modelagem da biomassa de Nectandra grandiflora (canela-amarela). Floresta, Curitiba, 2008. No prelo. Não corresponde, não achei este artigo na Floresta.

CHANG, M. Y. Seqüestro florestal do carbono no Brasil - dimensões políticas, socioeconômicas e ecológicas. São Paulo: Annablume, 2004. 278 p.

DURIGAN, M. E. Florística, dinâmica e análise protéica de uma Floresta Ombrófila Mista em São João do Triunfo-PR. 125 f. Dissertação (Mestrado em Engenharia Florestal) - Setor de Ciências Agrárias, Universidade Federal do Paraná, Curitiba, 1999.

INSTITUTO BRASILEIRO DE GEOGRAFIA E ESTATÍSTICA (IBGE). Manual técnico da vegetação brasileira. Rio de Janeiro, 1992. 92 p. (Série manuais técnicos em geociência, n.1).

INTERGOVERNMENTAL PANEL ON CLIMATE CHANGE (IPCC). Good Practice Guidance for Land-Use Change and Forestry. Geneva, 2003. 3.324 p.

KOEHLER, H. S.; WATZLAWICK, L. F.; KIRCHNER. F. F. Fontes e níveis de erros nas estimativas do potencial de fixação de carbono. In: SANQUETTA, C. R. et al. (ed.). As florestas e o carbono. Curitiba, 2002. p. 251-264.

LONGHI, S. J. A estrutura de uma floresta natural de Araucaria angustifolia (Bert.) O. Ktze, no sul do Brasil. 198 f. Dissertação (Mestrado em Engenharia Florestal) - Setor de Ciências Agrárias, Universidade Federal do Paraná, Curitiba, 1980.

LORENZI, H. Árvores brasileiras: manual de identificação e cultivo de plantas arbóreas nativas do Brasil. 2. ed. Nova Odessa, SP: Editora Plantarum, 1998 v. 2.

MARCENE, E. A.; CORTE, A. P. D.; SANQUETTA, C. R.; SCHNEIDER, C. R. Variação nos teores e estoque individuais de carbono fixado com o crescimento de Gmelina arborea Roxb. na região litorânea do Paraná Brasil. Scientia Forestalis, Piracicaba, n. 71, p. 55-63, 2006.

MARCHIORI, J. N. C. Dendrologia das angiospermas: das magnoliáceas às flacurtiáceas. Santa Maria, RS: Editora da UFSM, 1997. 271 p.

MIRANDA, D. L. C. Modelos matemáticos de estoque de biomassa e carbono em áreas de restauração florestal no sudoeste paulista. 113 f. Dissertação (Mestrado em Engenharia Florestal) - Setor de Ciências Agrárias, Universidade Federal do Paraná, Curitiba, 2008.

PIZATTO, W. Avaliação biométrica da estrutura e da dinâmica de uma Floresta Ombrófila Mista em São João do Triunfo - PR: 1995 a 1998. 172 f. Dissertação (Mestrado em Engenharia Florestal) - Setor de Ciências Agrárias, Universidade Federal do Paraná, Curitiba, 1999. 
RIBEIRO, A. B.; SILVA, D. H. S; BOLZANI, V. S. Antioxidant flavonol glycosides from Nectandra grandiflora (Lauraceae). Eclética Química, v. 27, n. especial, p. 35-44, 2002.

RODRÍGUEZ TELLO, J. C. Eficiência e custos de diferentes formas e tamanhos de unidades de amostra em uma floresta nativa de Araucaria angustifolia (Bert.) o Ktze no sul do Brasil. Dissertação (Mestrado em Engenharia Florestal) - Setor de Ciências Agrárias, Universidade Federal do Paraná, Curitiba, 1980.

SANQUETTA, C. R.; BALBINOT, R. Metodologias para determinação de biomassa florestal. In: SANQUETTA, C. R. et al. (ed.). As florestas e o carbono. Curitiba, 2002. p. 77-93.

SCHAAF, L. B. Florística, estrutura e dinâmica no período 1979-2000 de uma Floresta Ombrófila Mista localizada no sul do Paraná. 119 f. Dissertação (Mestrado em Engenharia Florestal) - Setor de Ciências Agrárias, Universidade Federal do Paraná, Curitiba, 2001.

SILVEIRA, P. Método indireto de estimativa do conteúdo de biomassa e do estoque de carbono em um fragmento de Floresta Ombrófila Densa. 112 f. Tese (Doutorado em Engenharia Florestal) - Setor de Ciências Agrárias, Universidade Federal do Paraná, Curitiba, Curitiba, 2008.

URBANO, E. Quantificação e estimativa aérea da biomassa e do carbono fixado em árvores de bracatingais nativos da região metropolitana de Curitiba. $140 \mathrm{f}$. Dissertação (Mestrado em Engenharia Florestal) - Setor de Ciências Agrárias, Universidade Federal do Paraná, Curitiba, 2007.

WATZLAWICK, L. F. Estimativa de biomassa e carbono em Floresta Ombrófila Mista e plantações florestais a partir de dados de imagens do satélite Ikonos II. $120 \mathrm{f}$. Tese (Doutorado em Engenharia Florestal) - Setor de Ciências Agrárias, Universidade Federal do Paraná, Curitiba, Curitiba, 2003.

WEBER, K. S.; SANQUETA, C. R.; MELLO, A. A.; WATZLAWICK, L. F.; BALBINOT, R. Variação nos teores de carbono orgânico em povoamento de Araucaria angustifolia (Bert.) O. Kuntze. Revista Brasil Florestal, Brasília-DF, v. 76, n. 1, p. 23-28, 2003. 